\title{
KHOMANANI: AN HIV AND AIDS COMMUNITY MOBILISATION PROGRAMME FOR RESOURCE-CONSTRAINED SETTINGS
}

\section{Tlangelani Shilubane, Stephan Geyer}

\section{INTRODUCTION AND PROBLEM FORMULATION}

An overview of HIV and AIDS statistics indicates that there were 31.6 million people living with HIV in 2010, and that $68 \%$ of those people were from Sub-Saharan Africa (UNAIDS, 2011:07). In South Africa, one of the countries in Sub-Saharan Africa, HIV prevalence among people between the ages of 15 and 49 has stabilised at $17.8 \%$, with the absolute number of people living with HIV (PLHIV) showing a steep increase of approximately 100000 additional PLHIV each year. The number of people aged 15 and older living with HIV is estimated to be 5300 000. These figures actually mean that one out of every six people with HIV in the world lives in South Africa (UNAIDS, 2011:21). The authors therefore postulate that these statistics encapsulate the devastation that HIV and AIDS is causing, particularly in South Africa, which arguably carries the heaviest HIV and AIDS burden in the world. Initially South Africa's efforts to mitigate the impact of HIV and AIDS were characterised by programme designs which followed an inflexible biomedical approach that did not focus on the influence of socio-economic and structural factors in addressing the pandemic. This situation, among others, contributed to raise the country's HIV infection growth rate to among the highest in the world (Kahn, 2006:4).

The increasing number of HIV infections and the impact of the pandemic on individuals and communities led to the establishment of the South African National AIDS Council (SANAC) and ultimately the National Strategic Plan on HIV, STIs and TB 2012-2016, became the cornerstone for the management of the pandemic in South Africa (South African National AIDS Council, 2011). The establishment of SANAC initiated an era in which South Africa engaged in a multisectoral approach towards the mitigation of HIV. SANAC served as a platform from which the South African government partnered with civil society sectors, such as non-governmental organisations (NGOs), faith-based organisations (FBOs), traditional leaders, traditional healers, women's groups, men's groups and business, as well as with higher education institutions in addressing the pandemic (Department of Health, 2007:7). The authors posit that the establishment of SANAC signified the government's commitment to addressing the socio-economic and structural factors that served as barriers for individuals and communities in HIV prevention. Additionally, this created the opportunity for the creation of social mobilisation programmes, such as LoveLife, Soul City and Khomanani, in an attempt to address the role of socio-economic and structural drivers within the context of HIV and AIDS (Seeley, Watts, Kippax, Russell, Heise \& Whiteside, 2012:1).

Khomanani is a Tsonga word meaning "caring together" and the campaign was developed in 2001 to address issues related to HIV and AIDS, sexually transmitted infections (STIs) and tuberculosis (TB) through activities that influenced and supported individual and social change, with the overall theme of "Moving the Nation to Act" 
(Department of Health, 2008). Essentially, Khomanani aims to reduce new HIV infections by increasing personal risk perception, including influencing social norms and values by advocating safer sexual health practices, and also linking people to prevention and care services (Department of Health, 2006b). According to Kippax (2012:1), interventions targeting social norms should be at the centre of HIV prevention, as preventing HIV involves engaging with social practices that affect the responses of individuals, communities and governments. When social factors such as poverty, gender, migration and stigma are addressed in HIV prevention, it helps to allow people to act in their own and their community's best interests (Auerbach, Justin, Parkhurst, Carlos \& Ca'ceres, 2011:1). Within this context the social work profession has a crucial role to play in coordinating interventions that target individuals within their environment to ensure that individuals' needs are addressed holistically and that communities are empowered to participate meaningfully in their own development.

The design of the Khomanani programme is grounded upon behavioural change communications theory as it is aimed at facilitating social movement and encouraging individual change in a supportive environment (Department of Health, 2006b). Furthermore, a closer look into the Khomanani programme design reveals a close resemblance to the Aids Risk Reduction Model. This model was developed by Cotania, Kegeles and Coates in 1992 and it provides a framework for understanding how people change their behaviours and beliefs through proposed stages of behaviour change. It explains and predicts the behaviour change efforts of individuals specifically in relation to the sexual transmission of HIV by incorporating several variables from other behaviour change theories. According to Collinge (2005:213), implementing Khomanani in alignment with these theoretical frameworks enabled the programme to address knowledge levels, attitudes and social norms in order to influence behaviour change.

Broadly defined, the Khomanani programme is divided into two focal areas that complement each other. The first aspect of the programme is 'below-the-line publicity', which mainly utilises television and radio. The second aspect focuses on the 'above-theline publicity', which entails social mobilisation through community activities that are delivered through face-to-face interaction by Khomanani Community Action Partners (KCPs) (Department of Health, 2005:6). The main objectives behind the establishment of the KCP programme were to provide face-to-face communication channels, to facilitate a groundswell of civil society response, and to establish community networks with the capacity to address and promote health-seeking behaviour in relation to HIV and AIDS (Department of Health, 2006b).

Within the framework of the development of the KCP programme 27 Khomanani community action teams were established in municipalities which were identified by the National Department of Health $(\mathrm{NDoH})$ as underserved and hard to reach. In total, three municipalities within each of the nine provinces of South Africa were targeted. In the Limpopo Province the municipalities were Bela Bela, Fetakgomo and Greater Letaba (Department of Health, 2006a:1). A brief profile of the Limpopo Province highlights that it is one of South Africa's most rural and underserved provinces. The province serves as South Africa's gateway to the rest of Africa, as it shares borders with 
Botswana, Zimbabwe and Mozambique (StatsSA, 2010). The authors thus believe that the high rates of migration, as well as the considerable levels of underdevelopment, greatly increase Limpopo Province's vulnerability to HIV infections. The province faces a number of development challenges, such as HIV, TB, poverty, inequality, dwellings without access to water inside homes and only limited access to flush toilets, while sustainable economic growth and job creation have not been established (Limpopo Provincial Government, 2009:7-9).

The Limpopo Province has approximately 5.4 million inhabitants (StatsSA, 2012) in five district municipalities, namely Sekhukhene, Capricorn, Waterberg, Vhembe and the Mopani District. The Mopani District is divided into four municipalities, namely Tzaneen, Giyani, Ba-Phalaborwa and the Greater Letaba. In 2009 the HIV prevalence amongst pregnant women in Limpopo Province was estimated at $21.3 \%$, while district prevalence rates were estimated as follows: Vhembe at $14.2 \%$, Capricorn at $23.7 \%$, Sekhukhene at 16.6\%, Mopani District at 26.2\%, and Waterberg at 28.7\% (Department of Health, 2010:34). Evidently Limpopo Province is not isolated from the broader negative impact that HIV and AIDS has within South Africa. The recognition of high HIV rates, coupled with the identification of the various developmental challenges as highlighted above, suggested the need to conduct the study in this area. In addition, Minkler (2005:3) asserts that there is insufficient information available on the effectiveness of HIV and AIDS community-based interventions. This consequently emphasised the need to explore the effectiveness of community interventions.

It should be noted that a communication survey was conducted in 2006 that evaluated the impact of communication programmes in South Africa. This survey was a collaborative study between Khomanani, Development Africa, the Centre for AIDS Development, Research and Evaluation (CADRE) and the Johns Hopkins University with the aim of evaluating the impact of various communication programmes in South Africa. It was found that over $90 \%$ of the respondents could recognise the Khomanani $\log 0$ and that $70 \%$ of them correctly identified a condom as a tool to prevent HIV infection (National HIV/AIDS Communication Survey, 2006). However, this study did not focus on matters such as linkages between the implemented interventions and HIV prevention efforts at community level, and the impact of social capital formation on HIV and AIDS mitigation. Therefore the researchers posit that significant questions remain to be answered, such as: "Was the KCP programme effective in mobilising communities towards HIV and AIDS prevention and care?" As a point of departure, this study aimed to find an answer to this question derived from the experiences of the Khomanani Community Action programme's partners within the Greater Letaba Municipality.

\section{RESEARCH QUESTION AND GOAL}

A research question is often used to focus exploratory studies as it refers to the problem that is to be investigated (Babbie, 2007:88-89). The following research question guided the study: "Based on the experiences of the partners, was the KCP programme effective in mobilising the Greater Letaba Municipality communities towards HIV and AIDS prevention and care?" 
The goal of this study was to explore the effectiveness of the KCP programme in the social mobilisation of communities in the Greater Letaba Municipality for HIV and AIDS prevention and care, as experienced by the partners.

\section{RESEARCH METHODOLOGY}

In accordance with a qualitative research approach (Babbie \& Mouton, 2001:76; Fouché $\&$ De Vos, 2011:95), an exploratory study was implemented in order to explore the effectiveness of the KCP in the Greater Letaba Municipality. A collective case study research design (Fouché \& Schurink, 2011:322) enabled the researchers to explore the effectiveness of the programme, based on the experiences of the partners involved. Data were collected through semi-structured interviews, guided by an interview schedule. The interviews were then transcribed and the data were content (thematically) analysed according to the nine steps of Creswell's process for qualitative data analysis (in Schurink, Fouché \& De Vos, 2011:403-419). The trustworthiness of the findings was ensured through member checking and reflection (Lietz, Langer \& Furman, 2006). Eleven participants, originating from Duiwelskloof, Sekgopo, Vuyani, and Peeha, which is to say four of the six sub-areas of the Greater Letaba Municipality implementing the KCP programme, took part in the study. All the sub-areas are rural with similar socioeconomic conditions and therefore related experiences and themes emerged from both government and civil society members. Data saturation was reached after 11 interviews. The participants were recruited through purposive sampling (Babbie, 2007:184). The criteria for the recruitment of participants were as follows:

- registered on the Provincial Department of Health database;

- members of the District AIDS Council;

- implementing HIV and AIDS programmes within the Greater Letaba Municipality for a minimum of four years; and

- willingness to provide informed consent.

Ethical considerations, specifically the avoidance of harm, informed consent, nonviolation of research participants' privacy, as well as anonymity and confidentiality, were taken into account (Babbie \& Mouton, 2001:524; Strydom, 2011:115-126; Welman, Kruger \& Mitchell, 2005:201). Before data collection this study received ethical clearance from the Research Ethics Committee of the Faculty of Humanities at the University of Pretoria. Prior to undertaking this study, the primary researcher was employed as an Assistant Director within the government AIDS Action Plan of the $\mathrm{NDoH}$. However, the study was conducted solely for research purposes with no financial or personal interest in the Khomanani programme.

\section{RESEARCH FINDINGS}

The research findings are outlined in two sections, namely (a) key biographical information on the participants; and (b) a presentation of the main themes that emerged. For the purpose of this paper, quotations are presented verbatim. However, comments made in an indigenous language of the area were translated into English. 


\section{Biographical profile}

The sample consisted of $18 \%(\mathrm{n}=2)$ participants who represented the Department of Health and $82 \%(\mathrm{n}=9)$ participants representing civil society. Civil society members, as defined by the SANAC structure composition, were represented as follows: two participants from the youth sector, two from community-based organisations (CBOs), two from Women in Partnership against Aids, one from Men in Partnership against AIDS, and two from FBOs. Furthermore, 27\% $(n=3)$ of the participants had between four to nine years experiences in implementing HIV and AIDS programmes. Seven $(64 \%)$ of the participants had 10 to 14 years' experience, $9 \%(n=1)$ of the participants had above 15 years' experience; the gender split of the participants was $36 \%(n=4)$ male and $64 \%(n=7)$ female. This gender split was not of major significance for the study as the main purpose was to ensure that the demographics of the sample were representative of the stakeholders from different sub-areas in the Greater Letaba Municipality rather than having an equal number of male and female participants. As such, the sample made provision for the experiences of various partners implementing HIV and AIDS programmes in the Greater Letaba Municipality.

\section{Themes and sub-themes}

As similar themes emerged for both civil society sector members and DoH officials, the findings are presented together.

Table 1 indicates the themes and sub-themes that emerged from the data.

TABLE 1

THEMES AND SUB-THEMES

\begin{tabular}{|c|c|}
\hline THEMES & SUB-THEMES \\
\hline $\begin{array}{l}\text { 1. Local relevance of } \mathrm{KCP} \text { activities in } \\
\text { the Greater Letaba Municipality }\end{array}$ & $\begin{array}{l}\text { 1.1 Appropriate context } \\
\text { 1.2 Appropriate content }\end{array}$ \\
\hline $\begin{array}{l}\text { 2. Implementing comprehensive and } \\
\text { interactive HIV and Aids activities }\end{array}$ & \\
\hline $\begin{array}{l}\text { 3. Factors contributing to the success of } \\
\text { the KCPs }\end{array}$ & $\begin{array}{l}\text { 3.1 Building social capital for HIV and } \\
\text { AIDS interventions } \\
\text { 3.2 Consultative partnerships }\end{array}$ \\
\hline 4. Programme sustainability & $\begin{array}{ll}4.1 & \text { Factors enabling sustainability } \\
4.2 & \text { Factors hindering sustainability }\end{array}$ \\
\hline
\end{tabular}

The themes and sub-themes depicted in Table 1 are discussed below.

\section{Theme 1: Local relevance of KCP activities in the Greater Letaba Municipality}

According to Bhana, Mckay, Mellins, Petersen and Bell (2010:6), successful HIV and AIDS interventions are informed by local knowledge with the support of empirical evidence to ensure cultural congruence. Creating an enabling environment by fostering appropriate context and content that were responsive to local dynamics was found to be fundamental in the implementation of the KCP programme within the Greater Letaba Municipality. 


\section{Sub-theme 1.1: Appropriate context}

Ziff, Harper, Chutuape, Deeds, Futterman, Francisco, Muenz and Ellen (2006:509) postulate that social mobilisation programmes that aim to influence behaviour change should remain appropriate to the context of the local communities at all times to inspire change. The majority of the participants strongly agreed that the KCP programme was locally relevant, largely because it was comprised of local community members, which enabled the programme to gain local support. This is in line with the argument of McKee, Bertrand and Bercker-Benton (2004:50) that it is essential that community members are active participants in community development initiatives, as this enhances community support and participation. Research participants motivated their assertions as follows:

"I think that the reason that the KCP programme could be able to conduct interesting and relevant activitie was because it was a programme implemented by local people. We were very proud to see our very own community members who were volunteers in the various CBOs being selected to be KCPs and to see them serving in their own community."

"Because KCPs know this community and respect its way of life, they encountered fewer communication problems with ordinary community members. This also helped them to talk to our people according to our way of life."

"At the end KCPs were able to get the traditional leaders to understand the severity of this HIV and AIDS issue; hence they were given a platform to address the community during the Moshate ${ }^{l}$ gatherings. My impressions are that the KCPs succeeded where others failed because they gained the community's respect and the community listened to them."

According to Chopra and Ford (2005:389), it is imperative that social mobilisation programmes understand local practices and preferences rather than relying on internationally generalised models of how people should behave and what they should want. Additionally, this is in line with the original intentions in the development of the $\mathrm{KCP}$ programme, as stated by the Department of Health (2006b:4), namely that KCP initiatives be designed to be responsive to local needs and conditions. The authors concur with Auerbach et al. (2011:1) that putting the community's interests at the forefront helps to create an enabling environment which is necessary for mitigating, if not eliminating, the pandemic.

\section{Sub-theme 1.2: Appropriate content}

The participants emphasised that KCPs were able to deliver factual and relevant content during their activities through reliance on the Khomanani Information Education and Communication (IEC) material relating to HIV and AIDS. The participants explained that this material improved the standard of communication as it encouraged uniformity

\footnotetext{
${ }^{1}$ A Northern Sotho word referring to "a meeting place" of local traditional leaders, heads of villages and ordinary community members. It is a place where important decisions affecting the community are referred to as a general assembly of the local people.
} 
in communicating messages and also minimising distortions and ambiguity. The use of and reliance on Khomanani IEC material by the Greater Letaba Municipality stakeholders contributed towards the standardisation of the content, such as posters in clinics, pamphlets delivered to individuals and public service announcements advertised on radio stations, and as such contributed towards the uniformity of the messages targeted at the various communities. In confirmation of this sub-theme, participants verbalised their experiences as follows:

"Khomanani had really good IEC material, I am talking about quality material which covered every aspect of HIV and AIDS from prevention, to treatment, care and support and even issues of human rights in relation to HIV and AIDS."

"Indeed, it is powerful that IEC material could be developed from a central place and be distributed anywhere in the country including rural communities such as ours free of charge. We might take this for granted, but that is very important for us as NGOs and CBOs, because we do not have the budget and expertise to produce such quality IEC material. Today wherever you go we are still dependent on this material only because Khomanani took the leadership role."

"I believe that all local organisations today appreciate the work that KCPs did in this community. They really brought us together and improved the quality of our work by building the capacity of the sectors to implement HIV and AIDS programmes by supplying us with IEC material. That professionalised the way we work and we all began to talk the same language as we served our community."

However, some participants suggested that, even though Khomanani produced and delivered good IEC material, there were some substantial limitations that affected the usefulness of this material at times. The participants raised concerns such as the following:

"Truly, Khomanani had lots of material and of very good quality. But the problem was not all the IEC materials were available in local languages. There were some editions, i.e. the stigma and human rights, which were only available in English; these were very valuable themes, especially in a highly stigmatised environment like ours, and however some community members cannot read English and therefore could not benefit from those materials."

The participants' reflections signify the great contribution that Khomanani made in harmonising HIV-prevention messages. Nevertheless, the accessibility of the IEC material in reaching more of the underserved, and especially illiterate, community members was significantly limited. The authors assert that producing certain materials in English only created a barrier to reaching the less educated community members and therefore limited the programme's ability to respond to pertinent needs of some key populations in this area. Therefore, the authors suggest that the KCP interpersonal communications approach became even more vital in engaging ordinary and less educated community members to support the weaknesses identified in the development 
of IEC material and to respond appropriately to community needs. The authors concur with Kippax (2012:5), who states that, within the context of HIV and AIDS programmes and services, social work should play an increasing role in ensuring that those programmes or interventions implemented always engage with the terrain in which individuals and communities operate, and in doing so also advance the human rights agenda.

\section{Theme 2: Implementing comprehensive and interactive HIV and AIDS activities}

All the participants interviewed were able to identify at least three HIV and AIDS prevention and care activities that were implemented by the KCPs, such as door-to-door visits, school outreach campaigns, street campaigns, educational workshops for traditional healers and stakeholders, clinic talks and health talks at Moshate. Auerbach et al. (2011:13) postulate that in order to deal effectively with the pandemic, methods and approaches beyond traditional conceptualisations are required that employ interactive methods and require the participation of various actors. UNAIDS (2004:130) concurs in stipulating that evidence has shown that only comprehensive approaches that integrate different activities in the intensification of HIV and AIDS interventions produce the best results. The participants articulated their experiences of the KCP activities as follows:

"KCP conducted HIV awareness talks at Moshate, where they addressed the community during these gatherings. You must understand that this is a very rural community and there are many restrictions on what is allowed or not. But once the community members saw that KCPs were allowed to talk about HIV issues at Moshate, they started to open up and after that it made it easier for KCPs to conduct door-to-door activities."

"For me the flagship of the KCP programme was the door-to-door activities. Through these, KCPs were able to take HIV and AIDS prevention messages to different homes and therefore access many people who would not have been reached through the other activities. Again because, door-to-door activities allowed KCPs to come into people's homes, this enabled KCPs to address and follow up on most issues that might have been left unattended in large crowds."

According to Adesegun and Jimoh (2003:320), HIV and AIDS behaviour change communication programmes that are able to combine mass media and activities that allow for face-to-face meetings often prove successful. Auerbach et al. (2011:1) agree, saying that after nearly three decades of the AIDS pandemic, there is an emerging consensus that comprehensive, strategic programming that relies on various methods to prevent HIV infections are more effective in the alleviation of HIV and AIDS. Participants attributed the effectiveness of the KCP programme to the link that existed between the visibility of the Khomanani social mobilisation, mass media campaigns and the level of community action that developed in the community to mitigate the pandemic.

\section{Theme 3: Factors contributing to the success of the KCPs}

Campbell, Nair and Maimane (2007:361) are of the opinion that social mobilisation is not necessarily a cheap way of delivering services and addressing social problems. 
Factors that contribute towards the success of community action in HIV and AIDS are focused on achieving social change and individual change through partnerships. Participants identified encouraging social capital and building consultative partnerships as the key factors that contributed to the success of the KCPs.

\section{Sub-theme 3.1: Building social capital for HIV and AIDS interventions}

Within the context of this study the conceptualisation of Gittell and Vidal (1998) was adopted, namely that social capital entails both bonding capital (that is where community members known to one another join together to address challenges and fulfil needs) as well as bridging capital (that is where people unknown to each other join together to establish initiatives that ultimately could be beneficial to the whole community, for example, volunteerism). Participants highlighted the fact that the KCP programme was active in building local community networks for the mitigation of HIV and AIDS in the Greater Letaba area. They expressed this as follows:

"What I can tell you is that bringing stakeholders together during workshops and through the stakeholders meetings greatly improved local collaboration and assisted in building cohesion amongst stakeholders. Again, this helped create unity around HIV and AIDS activities; it was as if all stakeholders, i.e. small CBOs, NGOs and government departments were singing from one (hymn) book."

"Local organisations today appreciate the work that KCPs did in this community. They really brought us together. The IEC material encouraged uniformity and the workshops built our capacity both within government and civil society to implement good HIV and AIDS programmes."

The KCP programme's ability to synergise HIV and AIDS activities by encouraging local collaboration among stakeholders, as well as building the capacity of stakeholders through workshops and the distribution of IEC material, illustrates an investment in building collective action directed at the alleviation of HIV and AIDS in the Greater Letaba area. Kippax (2012:1) suggests that effective prevention entails developing community capacity that is able to address people not only as individuals, but also as connected members of groups, networks and collectives who interact together. Within this study the development of social capital assisted in the creation of a network of supportive structures amongst the stakeholders, ensuring resource sharing and efficiencies in implementing HIV and AIDS activities. Against this backdrop the authors concur with Seeley et al. (2012:1) that interventions that harness social capital help build community "competence" and "resilience" by facilitating "programmes and processes that serve to buffer or ameliorate the impacts of social inequalities on people's health." Ensuring that locals are empowered to participate actively in their own development is central to social work service delivery in accordance with a social development approach.

\section{Sub-theme 3.2: Consultative partnerships}

Joint action that promotes local development essentially builds on and expands local knowledge, while responding to local demand (Hyman \& September, 2003:24). 
However, this is only possible when community groups work in partnership from the outset of the programme so that community members can be encouraged to contribute towards their own development (Phiri, Foster \& Nzima, 2001:7). Participants concurred that extensive consultations were held with the various HIV and AIDS programme implementers prior to the launch of the KCP programme. This enabled the KCP programme to gain the support of local NGOs and CBOs for its activities. According to the participants, the KCP programme managed to establish effective partnerships with HIV and AIDS programme stakeholders. Moreover, the programme cooperated with the various stakeholders in the implementation of HIV and AIDS activities and services through the Limpopo AIDS Council. Participants described KCP's partnerships and collaborative activities as follows:

"The strength of the KCP programme lay in its ability to develop good partnerships. I think that the KCP programme strengthened collaborations locally, firstly by selecting local community members to serve as KCPs and, secondly, by building the capacity of local groups to implement HIV and AIDS programmes. Automatically, people in the community had an interest in the success of the KCP programme and were eager to work together."

"I feel that the KCP partnerships did not only improve local collaboration, but also helped empower the community by building the capacity of the HIV and AIDS stakeholders. This was accomplished through the implementation of the HIV and AIDS workshops for the various local stakeholders such as traditional healers, traditional leaders and ordinary CBOs like us. Because of these workshops, stakeholders were able to share lessons learned and improve the way we do things towards the alleviation of HIV and AIDS in our community."

Piot and Seck (2001:1108) are of the opinion that the higher the degree of community participation in programmes, the greater the degree of programme effectiveness. The participants' observations reflect a positive experience concerning the collaborative activities of the KCP in the implementation of HIV and AIDS in the Greater Letaba Municipality. Furthermore, they highlighted some linkages between the level of social mobilisation activities and community action in the area. This is in line with the suggestion of Patel and Hochfeld (2008:195) that it is vital for social development programmes to encourage grassroots involvement and participation in order to build local capacity and to avoid imposing agendas. Besides that, existing local networks and partnerships are valuable as they enhance access to facilities, resources, knowledge and infrastructure that otherwise would not have been tapped effectively in addressing the impact of the developmental challenges faced by resource-constrained communities.

\section{Theme 4: Programme sustainability}

McKee et al. (2004:47) assert that when stakeholders within the community complement each other, together they are able to minimise chaos and confusion, and avoid wasting resources, hence enhancing the sustainability of financial, human and environmental resources. Within the context of HIV and AIDS there is a concern that most interventions are dependent on donor funding and therefore sustainability becomes a 
major feature, especially as biomedical interventions are often prioritised over community-based social mobilisation programmes (World Health Organisation, 2008:2). According to Campbell and Foulis (2004:6), sustainability requires a coordinated and synergised approach that balances the needs of community members with service providers' priorities. In this study participants identified those key factors that had a positive impact on the sustainability of the KCP programme, as well as those factors that served as barriers to the sustainability of the programme.

\section{Sub-theme 4.1: Factors enabling sustainability}

Participants identified the acknowledgement of cultural practices and encouragement of unity as factors that contributed towards the sustainability of the KCP programme. This is line with Phiri et al. (2001:34) who note that cultural perceptions impact significantly on programme sustainability because they have an effect on communities' receptiveness to HIV and AIDS awareness and prevention initiatives. Gruskin and Tarantola (2002:699) also agree by pointing out that cultural factors, such as social and religious dimensions, do impact on the sustainability of programmes as they are likely to influence communities' acceptance of programmes perceived to challenge cultural norms. Against this background, participants presented their examples on this issue as follows:

"I have seen some NGOs who have overlooked this issue and have come into this community and set up programmes, through their own people from the urban areas and six months or so later had to close down, because they took this matter for granted. Now KCPs have been around for over five years, and I can assure you it is mainly because they know this area and they are known in this area, as a result they are respected and trusted people and that is just how it is."

"Because KCPs understand this community they did not see traditional leaders and traditional healers as a threat, but they chose to engage them respectfully on these HIV and AIDS issues."

"Let me use the traditional healers' workshops on HIV and AIDS prevention as an example of approaching culture from an innovative angle. KCPs did not come here and start telling people not to go to traditional healers, which I think would have been rejected. But the KCPs made a positive impact by building the capacity of the healers with accurate HIV-prevention information and practices in order to assist people effectively."

McKee et al. (2004:42) argue that community development programmes that find it difficult to respond appropriately to local needs often view culture as a barrier to change instead of seeing it as an attitude that can work towards positive ends. The authors postulate that this review of the stakeholders' perceptions shows that the KCP programme was able to benefit from acknowledging local practices and this propelled the programme to find innovative approaches to respond appropriately to the needs of community members. According to Phiri et al. (2001:47), pre-existing resources in a community, such as skills, knowledge and practices, are valuable resources, mainly 
because they are most likely to enhance sustainability based on the fact that the local community identifies with, quickly adopts and hence takes ownership of such initiatives.

\section{Sub-theme 4.2: Factors hindering sustainability}

Since the negative impact of HIV and AIDS cuts across all sectors of society, the pandemic can only be addressed effectively through a comprehensive response that goes beyond the health sector (Kippax, 2012:6). This means that one of the great foundations for effectively addressing the pandemic is to mobilise the affected communities, with government at the forefront of the collaborative synergistic approach that has the support of all sectors (Piot \& Seck, 2001:968). Participants outlined the following factors as threats which hampered the sustainability of the KCP programme.

"You know, it is not that everything was not working, but I feel that the programme could have taken advantage of certain activities that proved to be effective in the community rather than continuing to conduct massive door-todoor which was very labour intensive with a few KCPs."

"Daily, KCPs proceeded to conduct door-to-door activities because it was said that it was part of the activities outlined in the national Khomanani strategy even when the need was always greater than the supply."

"The Municipality has Community Development workers; the Department of Health has Community Health Workers and let us not forget the KCPs. All these people are doing more or less the same things, yet there was no defined working relationship amongst these different service providers. Each of them went about doing their own thing, and I feel the community and also the programmes would have saved some resources if they had all collaborated together."

It seems that the strategy that guided the implementation of the KCP programme had been taken directly from the $\mathrm{NDoH}$ for implementation at the local level. Consequently, the strategy was rigid rather than flexible, as it did not allow for the prioritisation of key interventions to which the community was most responsive, but rather opted for the implementation of the broad strategy as a whole. The participants identified the inflexible programme design and lack of formal KCP programme integration into local, district, provincial and national government structural design as being the main threats to sustainability.

According to McKee et al. (2004:47), the sustainability of programmes can be enhanced through continuous and open communication between partners and the clarification of roles amongst the programme partners. The authors claim that participants raised valid issues that had an impact on the sustainability of the KCP programme in the Greater Letaba Municipality. Within this context, role clarification was vital in determining programme areas of comparative advantage, and also in ensuring the most efficient use of available resources, while minimising the duplication of services, which seems to be occurring in the Greater Letaba Municipality. 


\section{DISCUSSION}

HIV and AIDS present an extraordinary kind of developmental challenge in South Africa, and communities need a coordinated multidisciplinary approach to make an impact in eliminating new infections. Furthermore, effective HIV and AIDS programme design and implementation cannot continue to ignore the influence of social determinants such as gender, poverty, migration and human rights in determining the level and quality of health of individuals and communities (Auerbach et al., 2011:14; Kippax, 2012:1). In view of the findings of this research study, the authors agree with Piot and Seck (2001:12) that the HIV and AIDS crisis requires social mobilisation leadership from 'above' that links with the creative energy and leadership from the community at grassroots level. This means that there is a need for meaningful political leadership and commitment, including partnering with grassroots communities in the mitigation of the impact of HIV and AIDS. Essentially this also implies that local community members must be recognised as active and not passive recipients of services, which is central to the operationalisation of social development practices by the social work profession.

According to the research findings, social capital greatly enhanced the $\mathrm{KCP}$ programme's effectiveness. This was achieved by fostering consultative partnerships with all HIV and AIDS stakeholders in the Greater Letaba community under the leadership of the KCP. Mohan and Stokke (2000:253) assert that social capital promotes people's sense of ownership of the problem and encourages responsibility for contributing to its solution, which is likely to lead to the sharing of resources and increased efficiencies. The authors concur that locally responsive programmes should intentionally harness local leadership and encourage community participation, allowing programme implementation to unfold in a respectful, unimposing manner leading to greater community ownership. Indeed, individuals as well as community groups should be encouraged to work in collaboration with one another. This helps build unity and encourages collectivism by reducing the wastage of resources, which is essential in resource-constrained settings such as the Greater Letaba Municipality. In addition, strong social capital in communities living in poverty does not only have the potential to mitigate the pandemic, but it could also be channelled into socio-economic projects, for example, income-generating projects, and improving the social development of the community members (Midgley, 2010:183-186).

The research findings clearly indicated that developmental interventions can successfully use the influence of cultural precepts to encourage positive behaviour change. For example, the Greater Letaba Municipality KCPs initiated HIV and AIDS awareness campaigns at the gathering of traditional leaders by, amongst other things, providing educational workshops. This enabled the rural community to utilise traditional platforms to engage in discussions that challenged social norms regarding HIV prevention. This is a meaningful achievement and it affirms the position of McKee et al. (2004:132) that even though cultural perceptions and norms do not change overnight, with programmes that consistently address the knowledge and attitudes of community 
members, their practices could eventually be changed in working towards the prevention of HIV transmission.

This study found the Khomanani programme's strategy, which was developed nationally for local implementation, to be rigid and inflexible. Furthermore, the KCP programme lacked integration with the NDoH's broader service delivery framework, and thus the sustainability of the programme is at risk. Walker (2003:5) is of the opinion that the scale of the HIV and AIDS problem, coupled with limited resources, makes sound resource allocation critical.

The findings show that community mobilisation was a critical intervention in the mitigation of the pandemic, which is a complex, multifaceted phenomenon requiring the harmonisation of individual and community interventions to effect behaviour change. UNAIDS (2004:13) asserts that only comprehensive approaches that integrate interventions targeted at individual, community and structural levels will achieve the best results. It is against this background that the authors agree with Ziff et al. (2006:509) that community mobilisation that focuses on influencing social norms, building social capital, addressing gender dynamics and building knowledge levels has the potential to curb the spread of HIV over the long term.

If all the strengths of this programme, as indicated by the participants, are compared against factors that promote social mobilisation in resource-constrained communities (Botes \& Van Rensburg, 2000:52-54), the KCP programme could be regarded as being effective in mobilising the community of the Greater Letaba for HIV and AIDS prevention and care. The KCP programme respected the indigenous customs of community members; it involved a cross-section of interest groups in working collaboratively and it aimed to release the energy within the community without exploiting its members.

Social work is fundamentally concerned with promoting social justice by improving living conditions of the oppressed, the poor and the vulnerable (Banerjee, 2005:9). Therefore the authors think that social mobilisation offers the social work profession an opportunity to address the pandemic as well as its effects on people and society as a whole through a social development approach. Social development enables social workers to address the socio-economic determinants shaping the spread of HIV through, amongst other things, a multidisciplinary approach where different partners, representing both government and civil society, combine their efforts (welfare pluralism), the inclusion of local people in the planning and execution of services (democracy and participation), and the facilitation of an empowerment process which respects the cultural rights of local people (that is, a rights-based approach) (Patel, 2005:98-110).

The authors further state that social mobilisation is concerned with people's wellbeing by drawing on the participation of welfare consumers themselves in order to meet their unique developmental needs. This is in line with the statement by Green and Nieman (2003:167) that at the centre of the social work profession is the need to involve individual citizens and communities willingly and freely to work together with the various sectors of society to achieve development. Thus the authors postulate that, 
through social mobilisation, social workers have opportunities to lead the development and implementation of alternative innovative and participatory approaches that effectively complement biomedical models in working towards the elimination of the pandemic.

\section{CONCLUSIONS}

Before offering conclusions, the researchers draw attention to some of the limitations of this study: it was conducted with only 11 participants representing various sub-areas of the Greater Letaba Municipality, within one of the three areas in the Limpopo Province that implemented the $\mathrm{KCP}$ programme; hence the results cannot be generalised to stakeholders of the KCP programme in the rest of the Limpopo Province, or to South Africa as a whole. In addition, this study did not offer a voice to the direct beneficiaries, as it made provision only for the experiences of the partners/stakeholders in the $\mathrm{KCP}$ programme. Nevertheless, having noted the above, some valuable conclusions were reached and are summarised below.

- The KCP programme's ability to implement interactive, participatory and ageappropriate activities greatly increased participation amongst community members and community groups in striving towards the mitigation of the pandemic in the Greater Letaba Municipality.

- The KCP programme embraced the specific local context such as engaging the participation of traditional leaders and traditional healers in HIV prevention activities and content through the delivery of standardised quality HIV and AIDS IEC materials to all stakeholders and community members, although these material were not always available in the local language of the people. Through this, the programme gave priority to community needs and this assisted in creating that enabling environment which is necessary for the mitigation of HIV.

- Factors that positively contributed to the programme's effectiveness were the programme's initiative to build the capacity of local stakeholders on HIV-related issues through workshops, and its harnessing of social capital, allowing community groups to become active participants in HIV initiatives that enabled stakeholders to take ownership of activities in their different areas.

- The sustainability of the programme was positively enhanced through respect for, and acknowledgement of, local cultural practices and the encouragement of unity amongst stakeholders.

- On the other hand, the Khomanani programme's national strategy was found to be inflexible and rigid. It lacked integration with the government's broader service delivery framework. Resource constraints such as human capital were experienced, which impacted negatively on the ability to expand the programme to all areas to meet the needs within the various communities.

- The KCP programme's ability to reach vulnerable and underserved community members was significantly hampered by its inability to produce all the IEC material in the local language of the people and in accordance with their level of literacy, thus 
limiting the programme's ability to serve the needs of underserved and marginalised community members appropriately.

- While biomedical HIV interventions are important, they are not sufficient to alleviate new HIV infections as they are affected by social enablers that affect the attention and response from individuals and communities. Social mobilisation programmes are essential to attend to the role of social structures as the locus of change and the dynamics that affect social practices and community actions.

\section{RECOMMENDATIONS}

Based on these conclusions, the following recommendations are offered:

- The Khomanani social mobilisation programme should ensure that all IEC material is available in all official languages, and that it takes into account the literacy levels within the various communities to serve the needs of underserved and vulnerable people.

- The role of the KCP programme within the broader scope of the government's health and social services at the district, provincial or national levels should be clarified and formally communicated to all key stakeholders to provide role clarity, to position the programme within the area, to avoid duplication and to minimise wastage of resources.

- The social work profession should intensify its advocacy and leadership role within the multi-sectoral approach to highlight the role of social structures as the locus of change in the fight against HIV.

The following recommendations for future research are offered:

- There should be a follow-up study to determine the programme's effectiveness as perceived by the direct beneficiaries of the KCP service.

- A mixed-methods study should be carried out to establish the effectiveness of the KCP programme on a national basis. Such a study should ensure the inclusion of both partners and direct beneficiaries in the study while making provision for hard facts (statistics) and the experiences of research participants.

Finally, the authors conclude that, in the midst of great developmental challenges in the Greater Letaba Municipality, the KCP programme provided the inspiration for a collective effort towards the prevention of HIV. Therefore, against this background the authors assert that there is a need to intensify and extend HIV and AIDS social mobilisation interventions that utilise human rights-based approaches placing individuals at the centre of development in striving towards the alleviation of HIV and AIDS in South Africa, but especially in the remote, resource-constrained areas of the country. Social work professionals are well equipped to take up leadership roles within the multi-sectoral HIV and AIDS response to ensure that HIV prevention efforts are better informed by social approaches that recognise the role of socio-economic factors, social norms, social capital and their linkages to the level of community mobilisation and social movement. 


\section{REFERENCES}

ADESEGUN, O.F. \& JIMOH, A. 2003. The roles of behaviour change communication and mass media. Lagos, Nigeria: Development Communications Network.

AUERBACH, J.D., JUSTIN, J.D., PARKHURST, B., CARLOS, F. \& CA'CERES, C. 2011. Addressing social drivers of HIV/AIDS for the long-term response: Conceptual and methodological considerations. Global Public Health, 6(3):S293-S309.

BABBIE, E. 2007. The practice of social research $\left(11^{\text {th }}\right.$ ed). Belmont, CA: Thomson Learning.

BABBIE, E. \& MOUTON, J. 2001. The practice of social research. Cape Town: Oxford University Press.

BANERJEE, M.M. 2005. Social work, Rawlslian social justice and social development. Social Development Issues, 27(1):7-14.

BHANA, A., McKAY, M.M., MELliNS, C., PETERSEN, I. \& BELL, C. 2010. Family-based HIV prevention and intervention services for youth living in povertyaffected contexts. International AIDS Society, 13(2):2-8.

CAMPBELL, C. \& FOULIS, C. 2004. Creating contexts for effective home-based care of people living with HIV and AIDS in South Africa. Curationis, 23(7):5-14.

CAMPBELL, C., NAIR, Y. \& MAIMANE, S. 2007. Building contexts that support effective community responses to HIV/AIDS: a South African case study. Community Psychology, 39:347-363.

CHOPRA, M. \& FORD, N. 2005. Scaling up health promotion interventions in HIV/AIDS: challenges for rights-based approaches. Health Promotion International, 20(4):383-389.

COLLINGE, J.A. 2005. Confronting HIV and AIDS through mass media and community action. South African Health Review, 202-223.

DEPARTMENT OF HEALTH. 2005. Dialogue for action ... dialogue for life. Khomanani campaign on HIV, STI, AIDS and TB 2001-2004. Pretoria: Government Printers.

DEPARTMENT OF HEALTH. 2006a. Khomanani makes a difference: impact assessment, Khomanani campaign 2004-2006. Pretoria: Government Printers.

DEPARTMENT OF HEALTH. 2006b. Khomanani goes face to face: talking with communities about HIV, AIDS, STIs and TB, June 2006. Pretoria: Government Printers.

DEPARTMENT OF HEALTH. 2008. What is Khomanani? [Online] Available: http://www.aidsinfo.co.za [Accessed: 10/10/2008]. 
DEPARTMENT OF HEALTH. 2010. National HIV and Syphilis prevalence survey, South Africa 2009. [Online] Available: http://www.doh.gov.za [Accessed: 12/10/2010].

FOUCHÉ, C.B. \& DE VOS, A.S. 2011. Formal formulations. In: DE VOS, A.S. (ed), STRYDOM, H., FOUCHÉ, C.B. \& DELPORT, C.S.L. Research at grass roots: for the social sciences and human service professions $\left(4^{\text {th }}\right.$ ed). Pretoria: Van Schaik Publishers.

FOUCHÉ, C.B. \& SCHURINK, W. 2011. Qualitative research designs. In: DE VOS, A.S. (ed), STRYDOM, H., FOUCHÉ, C.B. \& DELPORT, C.S.L. Research at grass roots: for the social sciences and human service professions $\left(4^{\text {th }}\right.$ ed $)$. Pretoria: Van Schaik Publishers.

GITTELL, R. \& VIDAL, A. 1998. Community organizing. California: Sage Publications.

GREEN, S. \& NIEMAN, A. 2003. Social development: good practice guidelines. Social Work/Maatskaplike Werk, 39(2):161-181.

GRUSKIN, S. \& TARANTOLA, D. 2005. HIV/AIDS health and human rights in resource constraint settings: a handbook for programs. [SI]: Family Health International.

KAHN, T. 2006. AIDS drive gets a new life. Business Day, 5 December, 4.

KIPPAX, S. 2012. Effective HIV prevention: the indispensable role of social science. Journal of the International AIDS Society, 15(2):17357.

LIETZ, C.A., LANGER, C.L. \& FURMAN, R. 2006. Establishing trustworthiness in qualitative research in social work: Implications from a study regarding spirituality. Qualitative Social Work, 5(4):441-458.

LIMPOPO PROVINCIAL GOVERNMENT. 2009. Limpopo employment, growth and development plan 2009-2014. [Online] Available: www.limpopo.gov.za/ docs/legdp\%202009-2014.pdf [Accessed: 05/11/2012].

MCKEE, N., BERTRAND, J.T. \& BERCKER-BENTON, A. 2004. Strategic communication in the HIV/AIDS epidemic. London: Sage Publications.

MIDGLEY, J. 2010. Community practice and developmental social work. In: MIDGLEY, J. \& CONLEY, A. (eds) Social work and social development: theories and Skills for Developmental Social Work. New York, N.Y.: Oxford University Press.

MINKLER, M. 2005. Community-based research partnerships: challenges and opportunities. Urban Health, 82:2-12.

MOHAN, G \& STOKKE, K. 2000. Participatory development and empowerment: the dangers of localism. Third World Quarterly, 21(20):247-268. 
PATEL, L. 2005. Social welfare and social development in South Africa. Cape Town: Oxford University Press.

PATEL, L. \& HOCHFELD, T. 2008. Indicators, barriers and strategies to accelerate the pace of change to developmental social welfare in South Africa. Social Work Practitioner-Researcher, 20(2):192-211.

PHIRI, S.N., FOSTER, G. \& NZIMA, M. 2001. Expanding and strengthening community action: scaling up community mobilization interventions. [SI:sn].

PIOT, P. \& SECK, A.M. 2001. International response to the HIV/AIDS epidemic: Planning for success. Policy Practice, 79(12):1106-1112.

SOUTH AFRICAN NATIONAL AIDS COUNCIL (SANAC). 2011. National Strategic Plan on HIV, STIs and TB 2012-2016. [Online] Available: http://www.doc.gov.za/docs/statsdocs/2012/NSPsum.pdf [Accessed: 03/11/2012].

SCHURINK, W., FOUCHÉ, C.B. \& DE VOS, A.S. 2011. Qualitative data analysis and interpretation. In: DE VOS, A.S. (ed), STRYDOM, H., FOUCHÉ, C.B. \& DELPORT, C.S.L. Research at grass roots: for the social sciences and human service professions $\left(4^{\text {th }}\right.$ ed). Pretoria: Van Schaik Publishers.

SEELEY, J., WATTS, C., KIPPAX, S., RUSSELL, S., HEISE, L. \& WHITESIDE, A. 2012. Addressing the structural drivers of HIV: A luxury or necessity for programmes? Journal of the International AIDS Society, 15(1):1-4.

STATSSA. 2010. Mid-year population estimates: 2010. [Online] Available: http://www.statssa.gov.za [Accessed: 21/09/2011].

STATSSA. 2012. Census 2011: highlights of key results. [Online] Available: http://www.statssa.gov.za/census2011 [Accessed: 03/11/2012].

STRYDOM, H. 2011. Ethical aspects of research in the social sciences and human service professions. In: DE VOS, A.S. (ed), STRYDOM, H., FOUCHÉ, C.B. \& DELPORT, C.S.L. Research at grass roots: for the social sciences and human service professions $\left(4^{\text {th }}\right.$ ed). Pretoria: Van Schaik Publishers.

UNITED STATES AGENCY FOR INTERNATIONAL DEVELOPMENT (USAID). 2002. HIV/AIDS, Economics and Governance in South Africa: key issues in understanding response. Geneva: USAID.

UNAIDS. 2004. $4^{\text {th }}$ Global report on the global AIDS epidemic, June 2004. Geneva: UNAIDS.

UNAIDS. 2011. Report on the Global AIDS epidemic: Addressing societal causes of HIV risk and vulnerability. Geneva: UNAIDS.

WALKER, D. 2003. Cost and cost effectiveness of HIV/AIDS prevention strategies: is there evidence based? Health Policy and Planning, 18(1):4-7.

WELMAN, J.C., KRUGER, F. \& MITCHELL, B. 2005. Research methodology $\left(3^{\text {rd }}\right.$ ed). Cape Town: Oxford University. 
86

WORLD HEALTH ORGANIZATION. 2008. Public health approach to combating HIV/AIDS. New Delhi, Regional Office for South-East Asia: WHO Press.

ZIFF, A.M., HARPER, G.W., CHUTUAPE, K.S., DEEDS, B.G., FUTTERMAN, D., FRANSCISCO, V.T., MUENZ, L.R. \& ELLEN, J.M. 2006. Laying the foundation for connect to protect: Multi-site community mobilization intervention to reduce HIV/AIDS incidence and prevalence among urban youth. Journal of Urban Health, 83(3):506-521.

Ms Tlangelani Shilubane, MSW Postgraduate Candidate \& Dr Stephan Geyer, Department of Social Work and Criminology, University of Pretoria, Pretoria, South Africa. 